\title{
Primary hypothyroidism and chronotypes in adult women
}

Marilyn A. Arosemena ${ }^{1,5^{*}}$ (D, Alberto R. Ramos², Erin N. Marcus ${ }^{1}$, Katarzyna A. Slota ${ }^{4,6}$, Joseph Cheung ${ }^{3}$ and

Pablo R. Castillo ${ }^{3}$

\begin{abstract}
Objective: Abnormal thyroid function may disrupt sleep architecture. We aimed to determine the frequency of various chronotypes in women with hypothyroidism. We performed a single-center retrospective study at an ambulatory clinic from January 2013-December 2015. Participants were women with hypothyroidism. Chronotype was determined from the Munich ChronoType Questionnaire. The $x^{2}$ test was used to compare differences in clinical characteristics and sleep patterns in early and intermediate/late chronotypes. The $t$ test was used to compare differences between means.

Results: We evaluated 99 patients (mean [SD], 56 [7] years): calculated chronotype revealed: 56\% early, 38\% intermediate and $6 \%$ late. Analysis with the $x^{2}$ test showed significant differences between early and intermediate/late calculated chronotypes for sleep latency $(P=0.01)$, light exposure $(P=0.009)$, and no alcohol intake $(P=0.001)$. $t$ test showed the following differences in mean (SD) between chronotypes: sleep duration, 7.30 (1.39) hours (early chronotype) and 7.04 (2.06) hours (intermediate/late); body mass index (BMI), 29.4 (7.3) (early) and 31.1 (6.8) (intermediate/ late); and TSH level, 2.89 (3.69) $\mathrm{mIU} / \mathrm{L}$ (early) and 1.69 (1.41) mIU/L (intermediate/late). Early chronotypes were frequent in women with hypothyroidism. Light exposure and BMI may influence chronotypes in patients with hypothyroidism; findings are consistent with healthier behaviors in patients who tend toward morningness.
\end{abstract}

Keywords: Chronotypes, Circadian rhythm, Hypothyroidism, Sleep-wake phase

\section{Introduction}

Circadian rhythms, which are genetically determined intrinsic systems that influence the sleep-wake cycle, are critical for health and optimal organ function. The circadian clock controls physiology at many levels, partly through the hypothalamic-pituitary-peripheral organ axes. An excess or a deficit of hormones can disrupt sleep architecture [1].

Chronotypes are defined by the timing of sleep onset, wakefulness and behavior (early vs. late activities). Chronotypes are classified as early (morningness) to

\footnotetext{
*Correspondence: marilynarosemena@gmail.com

${ }^{1}$ Division of General Internal Medicine, Jackson Memorial Hospital, Miami, FL, USA
}

Full list of author information is available at the end of the article describe those who go to bed early and wake up early; late (eveningness) to describe those who go to bed late and wake up late; and intermediate. Patients with hypothyroidism have an increased risk for sleep disturbances $[2,3]$. However, a paucity of information exists on the relationship between chronotypes and thyroid disease. Hypothyroidism is more common in females, and young females tend to have an early chronotype that can change to a late chronotype with older age [4-6].

This study aimed to determine the chronotypes in women with hypothyroidism and the association of the chronotypes with demographic and clinical characteristics. In recognition of the impact of aging, we hypothesized that patients with hypothyroidism would more likely have late chronotype. 


\section{Main text \\ Methods \\ Population}

We evaluated 99 patients at an urban ambulatory center who were identified through electronic health records (EHR). Patients were women, age 18 to 65 , who had clinical hypothyroidism and were treated with levothyroxine from January 1, 2013, through December 31, 2015. Only women were selected because of higher hypothyroidism prevalence (female to male ratio 4-6:1) [7]. Exclusion criteria: shift workers, diagnosis of sleep apnea in the preceding 2 months and primary hypersomnia.

One of the authors tried to contact 450 patients by phone. Participants were asked questions from the Munich ChronoType Questionnaire (MCTQ). Of the 450 patients, 351 were excluded: 203 did not answer the phone; 12 declined to answer; 5 had sleep apnea; 6 shift workers; 3 were pregnant; 4 had a mental disability preventing from answering questions; 116 were $>65$ years; 1 had died; 1 had a TSH of $118 \mathrm{mIU} / \mathrm{L}$.

\section{Outcome}

We used the MCTQ to quantitatively assess participant's sleep. MCTQ focuses on asking about work schedule, workdays, sleep timing preceding workdays, work-free days, and use of an alarm clock [1, 4-6].

Chronotype was defined by the timing of sleep onset and wakefulness. Self-defined (reported) chronotype was defined as the reported time when individuals preferred to perform certain activities: early, intermediate or late [8]. All analyses were made on workdays and work-free days. Data regarding sleep onset, duration, time in bed, sleep loss, light exposure, and chronotype were obtained. (Additional file 1: Table S1). Midsleep was defined as the midpoint between sleep onset and awakening. Calculated chronotype was computed from midsleep on work free days only; chronotype was categorized as early (<3 AM), intermediate (from 3-5 AM), and late (>5 AM). Chronotypes according to midsleep could be calculated only in patients without alarm use on weekends.

\section{Exposures and covariates}

The MCTQ included demographic questions and the patient's sleep schedule on workdays/work-free days, which included continuous variables such as time of going to bed, sleep latency, sleep end, sleep inertia, work schedule, and light exposure. Body mass index (BMI) was determined from the EHR and categorized as normal (18.5-25), overweight (25.1-30), or obese (>30). Categorical variables were alarm clock use (yes/no); use of stimulants such as coffee (cups daily, further differentiated into $0,1-3$ [light use], and $>3$ [heavy use]), current tobacco use (yes if $>1$ cigarette daily), alcohol (yes if $>1$ drink weekly), or drugs (yes/no); and sleep medications (self-defined). Calculated variables were obtained with MCTQ formulas.

In addition, we obtained clinical information from EHR: TSH (Thyroid stimulating hormone) (euthyroid, 0.27-4.20 $\mathrm{mIU} / \mathrm{L}$; hyperthyroid <0.27 $\mathrm{mIU} / \mathrm{L}$; hypothyroid $>4.20 \mathrm{mIU} / \mathrm{L}$ ); levothyroxine dose; presence of diabetes; and hemoglobin A1c (HbA1c). A diagnosis of diabetes was determined from EHR per the ADA guidelines, HbA1c level was recorded only for patients with diabetes (A1c $\leq 7 \%$ was considered well-controlled diabetes; HbA1c > 7\%, uncontrolled).

After answering the questionnaire, participants classified themselves into a chronotype: early, intermediate, or late.

\section{Statistical analysis}

Descriptive statistics included age, BMI, workdays per week, sleep schedule, tobacco use, alcohol use, sleep medication use, and reported chronotype. The $\chi^{2}$ test was used to determine differences in the proportion of clinical characteristics (categorical variables) and the chronotype categories of early and intermediate/late chronotypes. Intermediate and late chronotypes were grouped together as the number of patients with late chronotype was small. Calculated chronotype was chosen instead of reported as both correlated very well and calculated chronotype is an objective measure. The $t$ test was used to compare differences between means. For univariate analyses, we used Astatsa and Excel with an $\alpha$ level of 0.05 . To examine the determinants of calculated chronotype in our sample, we fitted logistic regression models to independently test the associations between each demographic, behavioral, and sleep risk factor. Two regression models were fitted for the outcome of calculated intermediate/late chronotype: (1) first model adjusted for age, BMI, and TSH; (2) second model adjusted for those 3 variables and for the use of alcohol and coffee. The variables included in the models were associated with the outcome in univariate analysis or were significantly different across the calculated chronotypes. SAS 9.4 software was used for the logistic regression models.

\section{Results}

99 patients met the inclusion criteria and answered the MCTQ. The mean (SD) age of the patients was 56.5 (7.0) years. The BMI category was obese for $40.4 \%$. Mean TSH was $1.43 \mathrm{mIU} / \mathrm{L}, 73.7 \%$ patients were biochemically euthyroid (Table 1). 
Table 1 Features of Female Patients With Hypothyroidism $(\mathrm{N}=99)$

\begin{tabular}{|c|c|c|}
\hline Feature & No & $\%$ \\
\hline \multicolumn{3}{|l|}{ Age, y } \\
\hline $22-59$ & 54 & 54.5 \\
\hline $60-65$ & 45 & 45.4 \\
\hline \multicolumn{3}{|l|}{ BMI } \\
\hline 18.5-25 (Normal) & 17 & 17.2 \\
\hline $\begin{array}{l}25.1-30 \text { (Over- } \\
\text { weight) }\end{array}$ & 42 & 42.4 \\
\hline >30 (Obese) & 40 & 40.4 \\
\hline \multicolumn{3}{|l|}{ Thyrotropin, mIU/L } \\
\hline$<0.27$ & 14 & 14.1 \\
\hline $0.27-4.20$ & 73 & 73.7 \\
\hline$>4.20$ & 12 & 12.1 \\
\hline \multicolumn{3}{|l|}{ Diabetes } \\
\hline Yes & 23 & 23.2 \\
\hline No & 76 & 76.8 \\
\hline \multicolumn{3}{|c|}{ Hemoglobin $A_{1 c}(n=23)$} \\
\hline$\leq 7 \%$ & 10 & 43.5 \\
\hline$>7 \%$ & 13 & 56.6 \\
\hline \multicolumn{3}{|c|}{ Levothyroxine dose, mcg } \\
\hline$<50$ & 3 & 3 \\
\hline $50-100$ & 62 & 62.6 \\
\hline$>100$ & 34 & 34.3 \\
\hline \multicolumn{3}{|c|}{ Workdays per week, no. } \\
\hline $0-2$ & 15 & 15.2 \\
\hline $3-5$ & 41 & 41.4 \\
\hline$>5$ & 43 & 43.4 \\
\hline \multicolumn{3}{|l|}{ Cigarette smoking } \\
\hline Yes & 6 & 6.1 \\
\hline No & 93 & 93.9 \\
\hline \multicolumn{3}{|l|}{ Alcohol intake } \\
\hline Yes & 17 & 17.2 \\
\hline No & 82 & 82.8 \\
\hline \multicolumn{3}{|c|}{ Coffee intake, no. of cups daily } \\
\hline 0 & 16 & 16.2 \\
\hline $1-3$ & 53 & 53.5 \\
\hline$>3$ & 30 & 30.3 \\
\hline \multicolumn{3}{|c|}{ Sleep medication (weekly) } \\
\hline Yes & 26 & 26.3 \\
\hline No & 73 & 73.7 \\
\hline \multicolumn{3}{|l|}{ Chronotype (reported) } \\
\hline Early & 63 & 63.6 \\
\hline Intermediate & 24 & 24.2 \\
\hline Late & 12 & 12.1 \\
\hline
\end{tabular}

Table 1 (continued)

\begin{tabular}{lll}
\hline & Median & Interquartile ranges \\
\hline $\begin{array}{l}\text { Workdays: time of } \\
\text { going to bed }\end{array}$ & $10: 45$ PM & (9PM-11PM) \\
$\begin{array}{l}\text { Workdays: sleep } \\
\text { latency, min }\end{array}$ & 40 & $(5-90)$ \\
Workdays: sleep end & $6: 30$ AM & $(5: 30$ AM-7AM) \\
$\begin{array}{l}\text { Workdays: sleep inertia, } \\
\text { min }\end{array}$ & 5 & $(3-15)$ \\
$\begin{array}{l}\text { Workdays: light expo- } \\
\text { sure, min }\end{array}$ & 30 & $(10-120)$ \\
$\begin{array}{l}\text { Work-free days: time of } \\
\text { going to bed }\end{array}$ & $10: 30$ PM \\
$\begin{array}{l}\text { Work-free days: sleep } \\
\text { latency, min }\end{array}$ & 30 & $(8 P M-10: 30 P M)$ \\
$\begin{array}{l}\text { Work-free days: sleep } \\
\text { end }\end{array}$ & $7: 05$ AM \\
$\begin{array}{l}\text { Work-free days: sleep } \\
\text { inertia, min }\end{array}$ & 5 & $(5-90)$ \\
$\begin{array}{l}\text { Work-free days: light } \\
\text { exposure, min }\end{array}$ & 30 & $(6 \mathrm{AM}-8 \mathrm{AM})$
\end{tabular}

$B M I$ body mass index (calculated as weight in kilograms divided by height in meters squared)

MCTQ responses regarding work-days and work-free days bed time, sleep latency, sleep end and inertia are seen in Table 1.

Most patients reported working at home (53.5\%). Most patients did not smoke (93.9\%), or drink alcohol (82.8\%), $53.5 \%$ drank $1-3$ cups of coffee daily, $26.3 \%$ used sleep medication at least once weekly for insomnia. The most commonly used medications were melatonin, zolpidem, diphenhydramine, and benzodiazepines. (Table 1).

Analysis of daily schedules showed that for the largest percentages of patients, sleep onset occurred from 9:01 to $11 \mathrm{PM}$ on workdays (46.5\%) and from 11:01 PM to 1 AM on work-free days (43.4\%); sleep duration was 7-8 h on workdays (40.4\%) and on work-free days (38.4\%); and 8 to $10 \mathrm{~h}$ was spent in bed on workdays $(56.6 \%)$ and on work-free days (53.5\%). For the largest percentages of patients, midsleep occurred $<3$ AM on workdays (59.6\%) but between 3 and 5 AM on work-free days (47.5\%). For the largest percentages of patients, average weekly sleep duration was $<7 \mathrm{~h}(38.4 \%)$, weekly sleep loss was $<1 \mathrm{~h}$ (83.8\%), and average weekly light exposure was $>40 \mathrm{~min}$ (47.5\%). 
Table 2 Chronotypes and sleep patterns of female patients with hypothyroidism $(\mathrm{N}=81)$

\begin{tabular}{|c|c|c|c|c|c|c|c|}
\hline \multirow[t]{2}{*}{ Feature } & \multicolumn{4}{|c|}{ Patients with chronotype, $\%$} & \multicolumn{3}{|c|}{ Patients with chronotype, $\%$} \\
\hline & Early & Intermediate & Late & $P$ value & Early & Intermediate/late & $P$ value \\
\hline Age, y & & & & 0.82 & & & 0.23 \\
\hline $22-59$ & 30.8 & 18.5 & 3.7 & & 28.9 & 41.7 & \\
\hline $60-65$ & 24.7 & 19.7 & 2.5 & & 71.1 & 58.3 & \\
\hline $\mathrm{BMI}$ & & & & 0.12 & & & 0.052 \\
\hline 18.5-30 (Ideal and overweight) & 39.5 & 18.5 & 3.7 & & 71.1 & 50 & \\
\hline$>30$ (Obese) & 16 & 19.7 & 2.5 & & 28.9 & 50 & \\
\hline Thyrotropin, mIU/L & & & & 0.25 & & & 0.06 \\
\hline$<4.20$ & 44.4 & 35.8 & 6.2 & & 80 & 94.4 & \\
\hline$\geq 4.20$ & 11.1 & 2.5 & 0 & & 20 & 5.6 & \\
\hline Diabetes & & & & 0.64 & & & 0.81 \\
\hline Yes & 13.6 & 9.9 & 0 & & 24.4 & 22.2 & \\
\hline No & 41.9 & 28.4 & 6.2 & & 75.6 & 77.8 & \\
\hline Hemoglobin $\mathrm{A}_{1,} \%$ & & & & 0.07 & & & 0.09 \\
\hline$\leq 7$ & 10.5 & 26.3 & 0 & & 18 & 57.1 & \\
\hline$>7$ & 47.3 & 15.8 & 0 & & 81.8 & 8.3 & \\
\hline Levothyroxine dose, mcg & & & & 0.77 & & & 0.09 \\
\hline$<100$ & 28.4 & 17.3 & 3.7 & & 73.3 & 55.5 & \\
\hline$\geq 100$ & 27.2 & 20.9 & 2.5 & & 26.7 & 44.4 & \\
\hline Sleep latency, min & & & & 0.02 & & & 0.01 \\
\hline$<10$ & 19.8 & 3.7 & 1.2 & & 35.5 & 11.1 & \\
\hline$\geq 10$ & 35.8 & 34.6 & 4.9 & & 64.4 & 88.9 & \\
\hline Total time in bed, $\mathrm{h}$ & & & & 0.45 & & & 0.18 \\
\hline$<8$ & 23.5 & 11.1 & 1.2 & & 42.2 & 27.8 & \\
\hline$\geq 8$ & 32 & 27.2 & 4.9 & & 57.8 & 69.4 & \\
\hline Average weekly sleep duration, $\mathrm{h}$ & & & & 0.67 & & & 0.88 \\
\hline$<7$ & 22.2 & 17.3 & 1.2 & & 40 & 41.7 & \\
\hline$\geq 7$ & 33.3 & 20.9 & 4.9 & & 60 & 58.3 & \\
\hline Weekly sleep loss, h & & & & 0.14 & & & 0.47 \\
\hline$<1$ & 44.4 & 34.6 & 3.7 & & 80 & 86.1 & \\
\hline$\geq 1$ & 11.1 & 3.7 & 2.5 & & 20 & 13.9 & \\
\hline Average weekly light exposure, min & & & & 0.007 & & & 0.009 \\
\hline$<40$ & 20.9 & 23.5 & 6.2 & & 45.5 & 66.7 & \\
\hline$\geq 40$ & 34.6 & 14.8 & 0 & & 62.2 & 33.3 & \\
\hline Cigarette smoking & & & & 0.78 & & & 0.78 \\
\hline Yes & 3.7 & 3.7 & 0 & & 6.7 & 8.3 & \\
\hline No & 51.9 & 34.6 & 6.2 & & 93.3 & 91.7 & \\
\hline Alcohol intake & & & & 0.004 & & & 0.001 \\
\hline Yes & 2.5 & 11.1 & 2.5 & & 4.4 & 30.6 & \\
\hline No & 53 & 27.2 & 3.7 & & 95.6 & 69.4 & \\
\hline Coffee intake & & & & 0.49 & & & 0.22 \\
\hline No & 9.9 & 3.7 & 0 & & 17.8 & 8.3 & \\
\hline Yes & 45.6 & 34.6 & 6.2 & & 82.2 & 91.7 & \\
\hline Sleep medication & & & & 0.47 & & & 0.26 \\
\hline Yes & 12.3 & 13.6 & 1.2 & & 22.2 & 33.3 & \\
\hline No & 43.2 & 24.7 & 4.9 & & 77.8 & 66.7 & \\
\hline Sleep duration, h & & & & 0.63 & & & 0.96 \\
\hline$<7$ & 23.5 & 17.3 & 1.2 & & 42.2 & 41.7 & \\
\hline$\geq 7$ & 32 & 20.9 & 4.9 & & 57.8 & 58.3 & \\
\hline
\end{tabular}

$\mathrm{BMI}$, body mass index (calculated as weight in kilograms divided by height in meters squared) 
Table 3 Determinants of intermediate/late chronotype for women with hypothyroidism $(\mathrm{N}=81)$

\begin{tabular}{llc}
\hline Feature & \multicolumn{2}{l}{ Odds ratio (95\% Cl) } \\
\cline { 2 - 3 } & \multicolumn{1}{l}{ Model 1 } & \multicolumn{1}{c}{ Model 2 } \\
\hline Age in years & $0.9(0.8-1.0)$ & $0.9(0.8-1.0)$ \\
BMl & $1.07(0.9-1.1)$ & $1.08(0.9-1.1)$ \\
Thyrotropin level & $0.8(0.65-0.99)$ & $0.79(0.63-1.00)$ \\
Alcohol use (yes vs no) & - & $11.06(1.9-61.7)$ \\
Coffee use (yes vs no) & - & $1.79(0.35-8.9)$ \\
\hline
\end{tabular}

$\mathrm{BMI}$, body mass index (calculated as weight in kilograms divided by height in meters squared)

Reported chronotypes were early for $64 \%$ of patients, intermediate for $24.2 \%$, and late for $12.1 \%$. Midsleep occurred later on work-free days than on workdays for the largest percentages of patients, and midsleep was later on workdays and on work-free days for patients $<40$ years than for patients 40 years or older. Sleep duration was longer on work-free days than on workdays, and patients $>60$ years had shorter sleep duration than those $<40$ years.

Calculated chronotype was derived for 81 patients who did not report use of an alarm on weekends. Of the 81 patients, $56 \%$ had early, $38 \%$ had intermediate and $6 \%$ had late chronotype. Analysis with the $\chi^{2}$ test showed significant differences between the calculated early vs. intermediate vs. late chronotype: Sleep latency $\left(10^{3} \mathrm{~min}\right)$ was associated with the intermediate chronotype $(\mathrm{P}=0.02)$; no alcohol intake $(\mathrm{P}=0.004)$ and greater average weekly light exposure were associated with the early chronotype $(\mathrm{P}=0.007)$. Once intermediate/late chronotypes was grouped, similar results were found. Sleep latency was associated with the intermediate/late chronotype $(\mathrm{P}=0.01)$; no alcohol intake $(\mathrm{P}=0.001)$ and greater average weekly light exposure were associated with the early chronotype $(\mathrm{P}=0.009)$ (Table 2$)$.

Use of the t test showed the following differences in the mean (SD) between calculated chronotypes: sleep duration, 7.30 (1.39) hours (early chronotype) and 7.03 (1.41) hours (intermediate) and 7.01 (1.55) (late chronotype); age, 58.0 (5.7) years (early), 56.8 (7.4) years (intermediate) and 55.7 (6.9); BMI, 29.4 (7.3) (early), 30.2 (7.1) (intermediate) and 30.1 (5.4) (late); and TSH, 2.89 (3.69) (early), 2.3 (2.9) (intermediate) and 2.4 (2.2) (late) mIU/L. Linear regression of TSH and midsleep revealed $\mathrm{r}^{2}=0.07(\mathrm{p}=0.01)$ (Additional file 1: Fig. S1).

A lower BMI and higher TSH increased the odds of having an early chronotype. Alcohol consumption increased the odds for an intermediate/late chronotype (Table 3).

\section{Discussion}

To our knowledge, this is the first study to assess chronotypes in hypothyroidism. Even though patients with hypothyroidism have more sleep disturbances, there is a scarcity of data on the relationship of circadian patterns and thyroid disease $[9,10]$.

The key finding in our study is that patients with hypothyroidism are more likely to have an early chronotype. A possible explanation why higher TSH correlates with early chronotype may be related to higher TSH secretion in the early evening and peak secretion during the early part of the night [11]. Higher TSH seems to shift the circadian clock towards morningness. In addition, we found that higher BMI is associated with increased TSH.

In studies of chronotypes in healthy individuals and in patients with depression and inflammatory bowel disease, late chronotype is a marker of circadian misalignment (eg, social jet lag, sleep debt, and inconsistent meal timing) $[12,13]$. To our knowledge there are no comparable studies of chronotype in hypothyroidism. It is well known that, compared with people who have an early chronotype, people who have a late chronotype are more likely to have unhealthy behaviors and higher risk for obesity. In a prior study, women with a late chronotype had larger weight gains and higher BMI than women who had an early chronotype [14]. Similar observations have been made with patients with hypothyroidism and an intermediate/late chronotype.

In the present study, most patients had a normal TSH, which indicates euthyroid state; this may explain why most patients have an early chronotype [14]. However, in patients with normal thyroid glands, circulating TSH have a clear daily rhythm that is disrupted in patients with hypothyroidism [15]. This disruption is unlikely to be mitigated by standard doses of levothyroxine; thus, it is possible that continued variance in thyroid hormone during the day may lead to a change in chronotype.

Chronotypes are influenced by the environment, society, and medical conditions. Brain cortical thickness varies between people with different chronotypes [16], and an early chronotype is associated modestly with a lower risk of depression, but the mechanism is unclear [17] and the implications are partially uncertain.

Early chronotypes were more frequent in this sample of women with hypothyroidism. Light exposure, BMI, and lack of thyroid hormone rhythmicity may influence chronotypes in women who have hypothyroidism. Our findings are consistent with the observation in other studies that healthier behaviors are more common among patients who have a tendency toward morningness. 


\section{Limitations}

Limitations include a small sample size of female patients from an urban sample, which limits the implications to other populations. The patients were at a low-income clinic, mostly uninsured whose literacy level may be low. A subject with a TSH higher than 20 was excluded (outlier for linear regression analysis) but results with/ without outlier were the same. Many patients reported adequate sleep onset, latency, and duration, yet some reported waking up in the middle of the night, which may have interfered with sleep quality. A considerable proportion of patients were obese and responses may have been confounded by undiagnosed sleep apnea. The present study did not exclude patients on sleep medications. Agerelated changes in sleep propensity may have contributed to awakening early in the morning, with phase-advanced in older patients; nevertheless, our patients awakened early regardless of age after we controlled for age in our statistical models [18].

Sunlight and latitude are important in the sleep-wake cycle, chronotype is affected by geography, and people living in higher latitudes have a tendency toward eveningness [19]. Our study was conducted in Florida, where the latitude is lower than most US cities, so more hours of sunlight may have influenced chronotype in our sample.

\section{Abbreviations \\ EHR: Electronic health record; MCTQ: Munich ChronoType Questionnaire; BMI: Body mass index (calculated as weight in kilograms divided by height in meters squared); TSH: Thyroid stimulating hormone; $\mathrm{HbA}_{1 c}$ : Hemoglobin $\mathrm{A}_{1 c}$}

\section{Supplementary Information}

The online version contains supplementary material available at https://doi. org/10.1186/s13104-022-05934-3.

Additional file 1: Table S1. Munich ChronoType Questionnaire Variables. Figure S1. Linear regression between TSH and midsleep

\section{Acknowledgements}

Not applicable.

\section{Authors' contributions}

MAA performed conception or design of the work, data collection, drafting the article, critical revision of the article and final approval of the version to be published. ARR performed drafting the article, statistical analysis and final approval of the version to be published. ENM performed drafting the article and final approval of the version to be published. KAS performed drafting the article and final approval of the version to be published. JC performed drafting the article, statistical analysis, critical revision of the article and final approval of the version to be published. PRC did the conception or design of the work, drafting the article, critical revision of the article and final approval of the version to be published. All authors read and approved the final manuscript.

\section{Funding}

This research did not receive any specific grant from any funding agency in the public, commercial, or not-for-profit sector.

\section{Availability of data and materials}

Due to patient privacy we cannot share PHI. All data is shown in Table 1. We will be able to provide only de-identified data of our patients to confirm/ reproduce analysis. These could be requested by sending an email to the corresponding author Dr. Arosemena.

\section{Declarations}

Ethics approval and consent to participate

The University of Miami Institutional Review Board approved the study.

\section{Consent for publication}

Not applicable.

\section{Competing interests}

The authors declare that they have no competing interests regarding the publication of this article.

\section{Author details}

${ }^{1}$ Division of General Internal Medicine, Jackson Memorial Hospital, Miami, FL, USA. ${ }^{2}$ Department of Neurology, University of Miami, Miami, FL, USA. ${ }^{3}$ Division of Pulmonary, Allergy and Sleep Medicine, Mayo Clinic, Jacksonville, FL, USA. ${ }^{4}$ Mayo Clinic School of Graduate Medical Education, Mayo Clinic College of Medicine and Science, Jacksonville, FL, USA. ${ }^{5}$ Endocrinology, Diabetes, and Metabolism, University of Chicago, Chicago, IL, USA. ${ }^{6}$ Department of Neurology and Sleep Medicine Program, University of Utah, Salt Lake City, UT, USA.

Received: 12 October 2021 Accepted: 28 January 2022

Published online: 14 February 2022

\section{References}

1. Roenneberg T, Wirz-Justice A, Merrow M. Life between clocks: daily temporal patterns of human chronotypes. J Biol Rhythms. 2003;18(1):80-90.

2. Krishnan PV, Vadivu AS, Alappatt A, Kameswaran M. Prevalence of sleep abnormalities and their association among hypothyroid patients in an Indian population. Sleep Med. 2012;13(10):1232-7.

3. Bruyneel M, Veltri F, Poppe K. Prevalence of newly established thyroid disorders in patients with moderate-to-severe obstructive sleep apnea syndrome. Sleep Breath. 2019;23(2):567-73.

4. Fischer D, Lombardi DA, Marucci-Wellman H, Roenneberg T. Chronotypes in the US—influence of age and sex. PLoS ONE. 2017;12(6): e0178782.

5. Maierova L, Borisuit A, Scartezzini JL, Jaeggi SM, Schmidt C, Munch M. Diurnal variations of hormonal secretion, alertness and cognition in extreme chronotypes under different lighting conditions. Sci Rep. 2016;6:33591

6. Merrow M, Spoelstra K, Roenneberg T. The circadian cycle: daily rhythms from behaviour to genes. EMBO Rep. 2005;6(10):930-5.

7. Li H, Li J. Thyroid disorders in women. Minerva Med. 2015;106(2):109-14.

8. Levandovski R, Sasso E, Hidalgo MP. Chronotype: a review of the advances, limits and applicability of the main instruments used in the literature to assess human phenotype. Trends Psychiatry Psychother. 2013;35(1):3-11.

9. Li N, Heizhati M, Sun C, Abulikemu S, Shao L, Yao X, et al. Thyroid stimulating hormone is increased in hypertensive patients with obstructive sleep apnea. Int J Endocrinol. 2016;2016:4802720.

10. Zhang M, Zhang W, Tan J, Zhao M, Zhang Q, Lei P. Role of hypothyroidism in obstructive sleep apnea: a meta-analysis. Curr Med Res Opin. 2016;32(6):1059-64.

11. Bellastella G, Maiorino MI, Scappaticcio L, De Bellis A, Mercadante S, Esposito K, Bellastella A. Chronothyroidology: chronobiological aspects in thyroid function and diseases. Life (Basel, Switzerland). 2021;11(5):426.

12. Chakradeo PS, Keshavarzian A, Singh S, Dera AE, Esteban JPG, Lee AA, et al. Chronotype, social jet lag, sleep debt and food timing in inflammatory bowel disease. Sleep Med. 2018;52:188-95.

13. Haraden DA, Mullin BC, Hankin BL. The relationship between depression and chronotype: a longitudinal assessment during childhood and adolescence. Depress Anxiety. 2017;34(10):967-76. 
14. Maukonen M, Kanerva N, Partonen T, Mannisto S. Chronotype and energy intake timing in relation to changes in anthropometrics: a 7-year followup study in adults. Chronobiol Int. 2019;36(1):27-41.

15. Ikegami K, Refetoff S, Van Cauter E, Yoshimura T. Interconnection between circadian clocks and thyroid function. Nat Rev Endocrinol. 2019;15(10):590-600.

16. Rosenberg J, Jacobs HIL, Maximov II, Reske M, Shah NJ. Chronotype differences in cortical thickness: grey matter reflects when you go to bed. Brain Struct Funct. 2018;223(7):3411-21.

17. Vetter C, Chang SC, Devore EE, Rohrer F, Okereke OI, Schernhammer ES. Prospective study of chronotype and incident depression among middle- and older-aged women in the Nurses' Health Study II. J Psychiatr Res. 2018;103:156-60

18. Haimov I, Lavie P. Circadian characteristics of sleep propensity function in healthy elderly: a comparison with young adults. Sleep. 1997;20(4):294-300.

19. Miguel M, Oliveira VC, Pereira D, Pedrazzoli M. Detecting chronotype differences associated to latitude: a comparison between Horne-Ostberg and Munich Chronotype questionnaires. Ann Hum Biol. 2014;41(2):105-8.

\section{Publisher's Note}

Springer Nature remains neutral with regard to jurisdictional claims in pub-

lished maps and institutional affiliations.

- fast, convenient online submission

- thorough peer review by experienced researchers in your field

- rapid publication on acceptance

- support for research data, including large and complex data types

- gold Open Access which fosters wider collaboration and increased citations

- maximum visibility for your research: over 100M website views per year

At BMC, research is always in progress.

Learn more biomedcentral.com/submissions 